\title{
Concordance between the zinc sulphate flotation and centrifugal sedimentation methods for the diagnosis of intestinal parasites
}

\author{
Elizabete de Jesus Inês¹, Flavia Thamiris Figueiredo Pacheco', Milena Carneiro Pinto', \\ Patrícia Silva de Almeida Mendes ${ }^{2}$, Hugo da Costa-Ribeiro $\mathrm{Jr}^{2}$, \\ Neci Matos Soares ${ }^{1}$, Márcia Cristina Aquino Teixeira ${ }^{1}$ \\ 1 Departamento de Análises Clínicas e Toxicológicas, Faculdade de Farmácia, Universidade Federal da Bahia, \\ Bahia, Brasil \\ 2 Centro Pediátrico Professor Hosannah de Oliveira, CPPHO, Universidade Federal da Bahia, Salvador, Bahia, Brasil
}

Introduction: The diagnosis of intestinal parasitic infections depends on the parasite load, the specific gravity density of the parasite eggs, oocysts or cysts, and the density and viscosity of flotation or sedimentation medium where faeces are processed.

Objective: To evaluate the concordance between zinc sulphate flotation and centrifugal sedimentation in the recovery of parasites in faecal samples of children.

Materials and methods: Faecal samples of 330 children from day care centers were evaluated by zinc sulphate flotation and centrifugal sedimentation techniques. The frequencies of detection of parasites by each method were determined and the agreement between the diagnostic techniques was evaluated using the kappa index, with $95 \%$ confidence intervals.

Results: The faecal flotation in zinc sulphate diagnosed significantly more cases of Trichuris trichiura infection when compared to centrifugal sedimentation (39/330; $11.8 \%$ vs. $13 / 330 ; 3.9 \%, p<0.001$ ), with low diagnostic concordance between methods (kappa $=0.264 ; 95 \% \mathrm{Cl}: 0.102-0.427$ ). Moreover, all positive samples for Enterobius vermicularis eggs $(n=5)$ and Strongyloides stercoralis larvae $(n=3)$ were diagnosed only by zinc sulphate. No statistical differences were observed between methods for protozoa identification.

Conclusions: The results showed that centrifugal flotation in zinc sulphate solution was significantly more likely to detect light helminths eggs such as those of $T$. trichiura and $E$. vermicularis in faeces than the centrifugal sedimentation process.

Key words: Intestinal parasites/diagnosis; child; flotation; sedimentation.

doi: http://dx.doi.org/10.7705/biomedica.v36i4.2799

Concordancia entre los métodos de flotación con sulfato de zinc y sedimentación centrífuga
para el diagnóstico de parásitos intestinales

Introducción. El diagnóstico de infecciones parasitarias intestinales depende de la carga de parásitos, la densidad de la gravedad específica de los huevos, ooquistes o quistes de parásitos, y de la densidad y viscosidad de los reactivos de flotación o sedimentación usados para procesar las heces.

Objetivo. Evaluar la concordancia entre el método de flotación de sulfato de zinc y la sedimentación por centrifugación en la recuperación de parásitos en muestras fecales de niños.

Materiales y métodos. Se evaluaron las muestras fecales de 330 niños de guarderías mediante las técnicas de flotación con sulfato de zinc y de sedimentación por centrifugación. Se determinó la frecuencia de detección de parásitos con cada método y se evaluó la concordancia entre las técnicas de diagnóstico mediante el índice kappa, con intervalos de confianza del $95 \%$.

Resultados. Mediante la flotación fecal con sulfato de zinc, se diagnosticó un número significativamente mayor de casos de infección por Trichuris trichiura que con la sedimentación por centrifugación (39/330; $11,8 \%$ Vs. $13 / 330 ; 3,9 \%)(\mathrm{p}<0,001)$, con poco acuerdo entre los métodos (kappa=0,264; $\mathrm{IC}_{95 \%} 0,102$ $0,427)$. Además, todas las muestras positivas para huevos de Enterobius vermicularis $(n=5)$ y larvas de Strongyloides stercoralis $(n=3)$ se diagnosticaron solamente por sulfato de zinc. No se observaron diferencias estadísticamente significativas entre los métodos para la identificación de protozoos.

\footnotetext{
Author's contributions:

Márcia Cristina Aquino Teixeira and Patrícia Silva de Almeida Mendes designed the study and collected the samples.

Milena Carneiro Pinto, Elizabete de Jesus Inês and Flávia Thamires Figueiredo Pacheco performed the laboratory work.

Elizabete de Jesus Inês and Milena Carneiro Pinto analyzed the results.

Márcia Cristina Aquino Teixeira, Elizabete de Jesus Inês, Hugo Costa-Ribeiro Jr, Neci Matos Soares wrote the paper.
} 
Conclusiones. La flotación centrífuga en una solución de sulfato de zinc presentó una probabilidad significativamente mayor de detectar los huevos livianos de helmintos como T. trichiuray $E$. vermicularis en heces, que el proceso de sedimentación por centrifugación.

Palabras clave: parásitos intestinales/diagnóstico; niño; flotación;, sedimentación.

doi: http://dx.doi.org/10.7705/biomedica.v36i4.2799

The most commonly used parasitological diagnostic methods for detection of intestinal helminthic and protozoan infections in humans are inexpensive and simple to perform; however, they have important limitations, particularly regarding their sensitivity. Therefore, the use of more than one diagnostic method is necessary to detect different parasitic evolving forms, such as eggs, larvae, cysts, oocysts and trophozoites, due to the differences in size, morphology, density, and mobility among them. Moreover, the use of different parasitological methods is essential to improve sensitivity for helminth and protozoa diagnosis in patients with low parasite burdens (1).

Laboratory diagnosis of intestinal protozoa is performed by identifying the parasite cysts in faecal smears stained with iodine or by detecting the typical trophozoites in a wet or a permanent stained preparation (2). On the other hand, as the adult forms of most worms are rarely seen in faeces, the parasitological diagnosis relies on the identification of helminth eggs or larvae after concentrating the stools, which is usually realized by sedimentation or flotation techniques $(3,4)$.

Spontaneous sedimentation, centrifugal sedimentation, or formalin-ethyl acetate are widely used for the diagnosis of intestinal protozoa and helminths in human and animal stool samples (5-8). The faecal concentration methods based on sedimentation of parasites are useful for recovering heavy parasite eggs due to the concentration of the organisms in the sediment, whereas the centrifugal-flotation in zinc sulphate (9) is used preferentially to recover protozoa cysts because of the low density of parasitic forms as compared to the salt solution. The result is a clean preparation for microscopic examination with a minimal amount of faecal debris. For instance, if the density of a helminth egg is lower or close to the density of the flotation solution, it will float along with cysts of faecal homogenate.

Corresponding author:

Márcia Cristina Aquino Teixeira, Av. Barão de Jeremoabo, № 147, Campus Universitário de Ondina 40170-115, Salvador, Bahia, Brasil

Telephone: (5571) 3283 6950; fax: (5571) 32836949

marciat@ufba.br

Received: 13/05/15; accepted: 16/04/16
The purpose of this study was to evaluate the agreement between the zinc sulphate flotation and the centrifugal sedimentation for diagnosing protozoa and helminths in children's faecal samples.

\section{Materials and methods}

Faecal samples from 330 children attending day care centers in Salvador, Bahia, Brazil, whose ages ranged between 0 and 8 years, were examined by zinc sulphate flotation (ZS) (9) and centrifugal sedimentation (CS) (7) methods. Briefly, two grams of faeces were homogenized in $10 \mathrm{ml}$ of water and filtered through gauze for each diagnostic method. Subsequently, faecal homogenate was centrifuged in a $15 \mathrm{ml}$ tube for 2 minutes at $400 \mathrm{~g}$ twice and the sediment was examined by preparing wet mounts with iodine (CS) or resuspended in zinc sulphate solution $(1.18 \mathrm{~g} / \mathrm{mL})$ for the flotation process $(Z S)$. Faecal smears from the sedimentation technique were also stained by modified Ziehl-Neelsen (mZN) for coccidian diagnosis. Three slides per sample were examined with each technique.

We determined and compared the proportion of specific parasites identified by each diagnostic method in the faecal samples analysed. We evaluated the concordance between diagnostic methods by calculating kappa indices using the Graph Pad (San Diego, USA) statistical software. The reference kappa values were inferred as follows: $(<0)$ no agreement, (0-0.19) poor, (0.20-0.39) low, (0.40$0.59)$ moderate, $(0.60-0.79)$ substantial and $(0.80-$ 1.00 ) excellent agreement (10). We performed the statistical analysis of the frequencies of intestinal parasites and the concordance of diagnostic results between the two parasitological methods using the chi-square test; values of $p<0.05$ were considered statistically significant.

\section{Ethical aspects}

This study was approved by the Committee of Ethics in Research of the Department of Health of Bahia. Stools were collected from children only after obtaining a formal signed consent from their parents or legal guardians, whom also received the parasitological test results. All children were attended by a pediatrician and treated for enteroparasite infections when necessary. 


\section{Results}

Of the 330 children analyzed, $217(65.8 \%)$ were infected with at least one intestinal parasite regardless of the diagnostic method employed. According to the combined results of ZS and CS, the most frequent pathogenic protozoa identified were Giardia duodenalis (83/330; 25.1\%) and Blastocystis spp. (46/330; 13.9\%). Cryptosporidium spp. and Isospora belli infections were found in five (1.5\%) and in one child (0.3\%), respectively. Regarding helminths, Ascaris lumbricoides and Trichuris trichiura had the highest occurrence in faecal samples (table 1).

Concerning the frequency of specific parasites detected by each diagnostic method, ZS presented a similar proportion of $A$. lumbricoides and Hymenolepis nana cases compared to CS, or identified significantly more helminths such as $T$. trichiura $(p<0.001)$ (table 1$)$, with a low concordance between methods (kappa $=0.264$; $95 \% \mathrm{Cl}, 0.102-0.427$ ) (table 2). Moreover, all positive samples for Enterobius vermicularis eggs $(n=5)$ and Strongyloides stercoralis larvae $(n=3)$ were diagnosed only by ZS (table 1). As expected, Schistosoma mansoni egg samples were found solely in CS faecal sediments. The ZS method also detected most of the $G$. duodenalis cases $(74 / 83 ; 89.1 \%)$, compared to the CS technique $(67 / 83 ; 80 \%)$. Conversely, the latter identified more frequently the protozoan Blastocystis spp. in infected children $(38 / 46 ; 82.6 \%)$ vs. the ZS (33/46; $71.7 \%)$. However, no statistical differences were observed, and there was substantial agreement between methods for both parasites: kappa $=0.775$; 95\% Cl: 0.691-0.859, and kappa=0.669; 95\% Cl: $0.537-0.801$, respectively (table 2 ).

\section{Discussion}

The comparison of parasitological methods often requires study populations with high frequency of parasitic infections. In the present study, 217 out of 330 stools examined were positive for one or more intestinal parasites, allowing a correct assessment of the diagnostic concordance between the CS and ZS flotation parasitological techniques.

Usually, the goal in using the ZS flotation method is to improve the detection of protozoan cysts in stools because their densities are lower than the salt solution and they rise to the surface. Therefore, the increased quantity of $G$. duodenalis and amebae samples diagnosed in this study by ZS was expected, and it was in concordance with reports from other authors (11). Conversely, other studies, including this one, have shown that CS is a more effective technique for identification of Blastocystis spp. in faecal samples (12). The better performance of CS in Blastocystis spp. identification can be explained by the polymorphism of this protozoan, with different evolutionary forms (vacuolar, granular, amoeboid and cystic), and a wide range of sizes, varying from 2 to 200 micrometers (13-15). Moreover, the hypertonic zinc sulphate solution may not be appropriate for the detection of Blastocystis spp., due to the possibility of parasite membrane lysis $(16,17)$.

In this work, we did not compare CS and ZS methods for Cryptosporidium spp. diagnosis. In a previous report, we showed that the concentration

Table 1. Frequency of enteroparasites in faecal samples of 330 children from day care centers, analysed by zinc sulphate (ZS) flotation and centrifugal sedimentation (CS) methods

\begin{tabular}{|c|c|c|c|c|c|c|c|c|c|c|c|}
\hline \multirow[t]{3}{*}{ Protozoa } & \multicolumn{5}{|c|}{ Positivity } & \multirow[t]{3}{*}{ Helminths } & \multicolumn{5}{|c|}{ Positivity } \\
\hline & \multicolumn{2}{|r|}{ ZS } & \multicolumn{2}{|l|}{ CS } & \multirow{2}{*}{$\begin{array}{c}\frac{\mathrm{ZS}}{\overline{\mathrm{X}}} \\
\mathrm{CS}\end{array}$} & & \multicolumn{2}{|c|}{ ZS } & \multicolumn{2}{|r|}{ CS } & \multirow{2}{*}{$\begin{array}{c}\begin{array}{c}\mathrm{ZS} \\
\overline{\mathrm{X}} \\
\mathrm{CS}\end{array} \\
p\end{array}$} \\
\hline & $\mathbf{n}$ & $(\%)$ & $\mathbf{n}$ & $(\%)$ & & & $\mathbf{n}$ & (\%) & $\mathbf{n}$ & $(\%)$ & \\
\hline Giardia duodenalis* & 74 & (22.4) & 67 & (20.3) & 0.506 & Ascaris lumbricoides ${ }^{*}$ & 67 & $(20.3)$ & 68 & $(20.6)$ & 0.923 \\
\hline Endolimax nana* & 71 & (21.5) & 64 & $(19.4)$ & 0.499 & Trichuris trichiura* & 39 & (11.8) & 13 & (3.9) & $<0.001^{\star *}$ \\
\hline Entamoeba coli ${ }^{*}$ & 51 & $(15.4)$ & 47 & (14.2) & 0.661 & Hymenolepis nana* & 21 & $(6.4)$ & 17 & $(5.1)$ & 0.504 \\
\hline Blastocystis spp.* & 33 & (10.0) & 38 & (11.5) & 0.530 & Enterobius vermicularis & 5 & (1.5) & 0 & $(0.0)$ & $0.025^{* *}$ \\
\hline lodamoeba butschlii* & 25 & $(7.6)$ & 20 & $(6.1)$ & 0.440 & Strongyloides stercoralis & 3 & $(0,9)$ & 0 & $(0.0)$ & 0.083 \\
\hline $\begin{array}{l}\text { E. histolytica/dispar/ } \\
\text { moshkovskii" }\end{array}$ & 14 & $(4.2)$ & 14 & $(4.2)$ & 1.000 & Hookworm & 3 & $(0.9)$ & 1 & $(0.3)$ & 0.316 \\
\hline Chilomastix mesnilli & 3 & $(0.9)$ & 2 & $(0.6)$ & 0.653 & Schistosoma mansoni & 0 & $(0.0)$ & 2 & $(0.6)$ & 0.157 \\
\hline
\end{tabular}

${ }^{*} p<0.05$ : Parasites with statistically significant frequencies compared to total of parasitized children (217/330; $\left.68.5 \%\right)$, considering results of both parasitological methods. ${ }^{*} p<0.05$ : Statistically significant difference between ZS and CS methods for the diagnosis of Trichuris trichiura and Enterobius vermicularis; chi-square test. 
Table 2. Concordance between zinc sulphate flotation and centrifugal sedimentation for diagnosing protozoan cysts and helminth eggs in faeces

\begin{tabular}{|c|c|c|c|c|c|}
\hline & \multicolumn{3}{|c|}{ Zinc sulphate flotation } & \multirow[t]{2}{*}{${ }^{*}$ Kappa $(95 \%$ Cl) } & \multirow[t]{2}{*}{ Concordance level } \\
\hline & Positive & Negative & Total & & \\
\hline \multicolumn{6}{|c|}{ Centrifugal sedimentation } \\
\hline \multicolumn{6}{|c|}{ Giardia duodenalis } \\
\hline Positive & 58 & 9 & 67 & $0.775(0.691-0.859)$ & Substantial \\
\hline Negative & 16 & 247 & 263 & & \\
\hline Total & 74 & 256 & 330 & & \\
\hline \multicolumn{6}{|c|}{ Blastocystis spp. } \\
\hline Positive & 25 & 13 & 38 & $0.669(0.537-0.801)$ & Substantial \\
\hline Negative & 8 & 284 & 292 & & \\
\hline Total & 33 & 297 & 330 & & \\
\hline \multicolumn{6}{|c|}{ Entamoeba histolytica/dispar/moshkovskii } \\
\hline Positive & 14 & 0 & 14 & $1.000(1.000-1.000)$ & Excellent \\
\hline Negative & 0 & 316 & 316 & & \\
\hline Total & 14 & 316 & 330 & & \\
\hline \multicolumn{6}{|c|}{ lodamoeba butschlii } \\
\hline Positive & 17 & 3 & 20 & $0.738(0.590-0.886)$ & Substantial \\
\hline Negative & 8 & 302 & 310 & & \\
\hline Total & 25 & 310 & 330 & & \\
\hline \multicolumn{6}{|c|}{ Endolimax nana } \\
\hline Positive & 60 & 4 & 64 & $0.860(0.792-0.929)$ & Excellent \\
\hline Negative & 11 & 255 & 266 & & \\
\hline Total & 71 & 259 & 330 & & \\
\hline \multicolumn{6}{|c|}{ Entamoeba coli } \\
\hline Positive & 44 & 3 & 47 & $0.880(0.807-0.953)$ & Excellent \\
\hline Negative & 7 & 276 & 283 & & \\
\hline Total & 51 & 279 & 330 & & \\
\hline \multicolumn{6}{|c|}{ Ascaris lumbricoides } \\
\hline Positive & 55 & 13 & 68 & $0.767(0.680-0.854)$ & Substantial \\
\hline Negative & 12 & 250 & 262 & & \\
\hline Total & 67 & 263 & 330 & & \\
\hline \multicolumn{6}{|c|}{ Trichuris trichiura } \\
\hline Positive & 8 & 5 & 13 & $0.264(0.102-0.427)$ & Low \\
\hline Negative & 31 & 286 & 317 & & \\
\hline Total & 39 & 291 & 330 & & \\
\hline \multicolumn{6}{|c|}{ Hymenolepis nana } \\
\hline Positive & 17 & 0 & 17 & $0.888(0.780-0.996)$ & Excellent \\
\hline Negative & 4 & 309 & 313 & & \\
\hline Total & 21 & 309 & 330 & & \\
\hline
\end{tabular}

* Only parasites with significant frequencies and detected by both parasitological methods were included for evaluation of concordance by kappa index.

of oocysts by CS, followed by mZn staining, proved to be a suitable protocol for Cryptosporidium detection in human faeces (7). Moreover, the ZS method showed lower sensitivity and specificity compared to saturated sugar solution flotation technique for Cryptosporidium spp. diagnosis (18).

The effective recovery of parasite eggs and cysts depends on their own densities and on the density and viscosity of the flotation medium. Considering these issues, the choice of a flotation solution must be matched with the characteristics of particular parasite species for optimal results. In this study, the relatively heavy helminth eggs, such as those of $S$. mansoni, were only detected by CS due to their high density and subsequent tendency to settle along with various faecal debris (19). In addition, faecal components such as food debris, fat, bacteria, fungi, etc., may affect the performance of a specific parasitological method, which may interfere with the faecal concentration process as well as the microscopic visualization of the parasitic forms (7).

The specific gravities of helminth eggs have been determined previously using density gradients (20-22). In those studies, some eggs of animal or human helminths presented the following densities $\left(\mathrm{g} / \mathrm{cm}^{3}\right)$ : Ancylostoma duodenale and A. caninum, 1.05; A. lumbricoides, 1.11-1.13 (fertile) and 1.20 
(infertile) and A. suum, 1.13; E. vermicularis, 1.11; Trichuris suis, 1.13, T. vulpis, 1.14 and T. trichiura, 1.15. Considering the relatively lower density of helminth eggs compared to the zinc sulphate solution $\left(1.18 \mathrm{~g} / \mathrm{cm}^{3}\right)$, their tendency to float to the surface is expected. However, average dimensions of eggs may influence their flotation in salt or sugar solutions, as well as their sedimentation velocity in water (22). As we observed in our study, despite the closer specific gravity of $T$. trichiura eggs (size range $50 \times 22 \mu \mathrm{m}$ ) to $A$. lumbricoides eggs (size range $60 \times$ $45 \mu \mathrm{m}$ - fertile and $90 \times 40 \mu \mathrm{m}$ - infertile), there was no significant difference in the diagnosis of the latter between ZS or CS. It is also important to note that an $A$. lumbricoides female can eliminate 10 times more eggs than a $T$. trichuris female, favouring the identification by different diagnostic techniques.

When we analyzed the diversity of helminths identified by the method employed in this work, we noticed a higher frequency of $T$. trichiura eggs when diagnosed by ZS. Previous studies have shown that ZS is very effective in detecting $T$. vulpis infections in dogs (11). In our study, CS failed to detect 31 of 44 cases of trichiuriasis, which were diagnosed exclusively by ZS. Despite the lower detection of $T$. trichiura infected children, the CS method identified five positive cases that were not diagnosed by ZS. This emphasizes the need to combine two or more methods, always including a flotation technique, for diagnosing light helminth eggs in faecal samples. As discussed above, it is feasible that the variation on the egg size range of a specific parasite population and, consequently, its density, or the low parasite load in faeces, may have accounted for the five $T$. trichiura samples diagnosed only by CS.

It is also notable that the faecal analysis identified four additional $H$. nana, and exclusively five $E$. vermicularis and three $S$. stercoralis cases by the ZS flotation method. Diagnosis of $E$. vermicularis and $S$. stercoralis infections is usually based on the recovery of typical eggs on perianal skin using a transparent tape (23) and by the BaermannMoraes method (24), respectively, and rarely by sedimentation techniques. Thus, although it is a nonspecific laboratory tool for both parasites, the ZS may identify some enterobiasis and strongyloidiasis cases during coproparasitological analysis.

In conclusion, this study demonstrated that it is significantly more likely that the centrifugal flotation in zinc sulphate solution detect a faecal sample positive for $T$. trichiura or E. vermicularis than the centrifugal sedimentation process, whereas there were no significant differences between methods in the identification of other intestinal parasites, including $G$. duodenalis. Therefore, the use of both methods in the clinical laboratory will maximize the precision and improve the diagnosis of parasitic infections in children.

\section{Conflicts of interest}

The authors confirm that there are no conflicts of interest.

\section{Financial support}

This work was supported by the Fundação de Amparo à Pesquisa do Estado da Bahia (FAPESB) and Universidade Federal da Bahia (UFBA), Brazil.

\section{References}

1. John DT, Petri WA. Markell and Voge's Medical Parasitology. Ninth edition. Noida India: Saunders Elsevier; 2009. p. 463.

2. Collier L, Balows A, Sussman M. Topley and Wilson's Microbiology and Microbial Infections: Parasitology. Tenth edition. Washington, D.C.: Hodder Arnold; 2005. p. 912.

3. Garcia LS. Diagnostic Medical Parasitology. Fifth edition. Washington, D.C.: ASM Press; 1997. p. 937.

4. Cringoli G, Rinaldi L, Maurelli MP, Utzinger J. FLOTAC: New multivalent techniques for qualitative and quantitative copromicroscopic diagnosis of parasites in animals and humans. Nat Protoc. 2010;5:503-15. http://dx.doi.org/10. 1038/nprot.2009.235

5. Katagiri S, Oliveira-Sequeira TC. Comparison of three concentration methods for the recovery of canine intestinal parasites from stool samples. Exp Parasitol. 2010;126:214-6. http://dx.doi.org/10.1016/j.exppara.2010.04.027

6. Tello R, Terashima A, Marcos LA, Machicado J, Canales M, Gotuzzo E. Highly effective and inexpensive parasitological technique for diagnosis of intestinal parasites in developing countries: Spontaneous sedimentation technique in tube. Int J Infect Dis. 2012;16:414-6. http://dx.doi.org/10.1016/j. ijid.2011.12.017

7. Pacheco FT, Silva RK, Martins AS, Oliveira RR, AlcântaraNeves NM, Silva MP, et al. Differences in the detection of Cryptosporidium and Isospora (cystoisospora) oocysts according to the fecal concentration or staining method used in a clinical laboratory. J Parasitol. 2013;99:1002-8. http://dx.doi.org/10.1645/12-33.1

8. Rocha NO, Portela RW, Camargo SS, Souza WR, Carvalho GC, Bahiense TC. Comparison of two coproparasitological techniques for the detection of Platynosomum sp. infection in cats. Vet Parasitol. 2014;29:392-5. http://dx.doi.org/10. 1016/j.vetpar.2014.04.022

9. Faust EC, Sawitz W, Tobie J, Odom V, Peres C, Lincicome DR. Comparative efficiency of various techniques for the diagnosis of protozoa and helminth in feces. J Parasitol. 1939;25:241-62.

10. Landis JR, Koch GG. The measurement of observer agreement for categorical data. Biometrics. 1977;33:159-74. 
11. Zajac AM, Johnson J, King SE. Evaluation of the importance of centrifugation as a component of zinc sulphate fecal flotation examinations. J Am Anim Hosp Assoc. 2002;38:221-4. http://dx.doi.org/10.5326/0380221

12. Eymael D, Schuh GM, Tavares RG. Padronização do diagnóstico de Blastocystis spp. por diferentes técnicas de coloração. Rev Soc Bras Med Trop. 2010;43:309-12. http:// dx.doi.org/10.1590/S0037-86822010000300019

13. Pirajá SC, Jeremiah S. Blastocystis: Taxonomy, biology and virulence. Trop Parasitol. 2013;3:17-25. http://dx.doi. org/10.4103/2229-5070.113894

14. Tan KS. Blastocystis in humans and animals: New insights modern methodologies. Vet Parasitol. 2004;126:121-44. http://dx.doi.org/10.1016/j.vetpar.2004.09.017

15. Stenzel DJ, Boreham PFL, McDougall R. Blastocystis hominis revisited. Clin Microbiol Rev. 1996;9:563-84.

16. Alarcón RSR, Amato Neto V, Gakiya E, Bezerra RC. Observações sobre Blastocystis hominis e Cyclospora cayetanensis em exames parasitológicos efetuados rotineiramente. Rev Soc Bras Med Trop. 2007;40:253-5. http://dx.doi.org/10.1590/S0037-86822007000200024

17. Amato Neto VA, Alarcón RS, Gakiya E, Bezerra RC, Ferreira CS, Braz LM. Blastocistose: controvérsias e indefinições. Rev Soc Bras Med Trop. 2003;36:515-7. http:// dx.doi.org/10.1590/S0037-8682200300 0400014
18. Bhat SA, Dixit M, Juyal PD, Singh NK. Comparison of nested PCR and microscopy for the detection of cryptosporidiosis in bovine calves. J Parasit Dis. 2014;38:101-5. http://dx.doi. org/10.1007/s12639-012-0201-5

19. Scandrett WB, Gajadhar AA. Recovery of putative taeniid eggs from silt in water associated with an outbreak of bovine cysticercosis. Can Vet J. 2004;45:758-60.

20. Sawitz W. The buoyancy of certain nematode eggs. J Parasitol. 1942;28:95-102.

21. David ED, Lindquist WD. Determination of the specific gravity of certain helminth eggs using sucrose density gradient centrifugation. J Parasitol. 1982;68:916-9.

22. Mara D, Horan NJ. The handbook of water, wastewater and microbiology. Amsterdam: Academic Press; 2003.

23. Graham DF. A device for the diagnostic on the Enterobius vermicularis infection. Am J Trop Med Hyg. 1941;21:150-1.

24. Moraes RG. Contribuição para o estudo do Strongyloides stercoralis e da estrongiloidose no Brasil. Rev Serv Espec Saúde Pública 1948;1:507-624. 